\title{
Plataformas fact-checking: las fakes news desmentidas por Newtral en la crisis del coronavirus en España
}

\section{Fact-checking platform: the fakes news denied by Newtral in the coronavirus crisis in Spain}

\author{
Yaiza Pozo-Montesa ${ }^{a}$ Marina León-Manovela \\ a Departamento de Periodismo II, Facultad de Ciencias Sociales y de la Comunicación, Universidad del País Vasco, España
}

\section{Resumen}

Introducción: El fact-checking, o la verificación de datos, se ha convertido en una práctica periodística cada vez más en boga. Sin duda, una herramienta que ha demostrado ser necesaria para desmentir las fake news que circulan por las redes sociales, tal y como ha sucedido en el caso concreto de la crisis sanitaria del coronavirus. Objetivos: Analizar las características de las noticias falsas desmentidas por Newtral Media Audiovisual y determinar su tendencia durante las sucesivas prórrogas del Estado de Alarma. Metodología: Se han examinado 104 informaciones que hacen referencia al COVID-19 en España, desde el 14 de marzo hasta el 4 de mayo de 2020, mediante el análisis cuantitativo y cualitativo del estudio de caso. Resultados: Todas las fake news han convergido en diferentes redes sociales, pero el canal principal para su difusión ha sido WhatsApp, siendo el texto y el audio los formatos que han presentado una mayor manipulación. La temática predominante de los bulos ha sido la política y las falsas atribuciones a instituciones han logrado engañar a la ciudadanía. Conclusiones: El fact-checking constata su éxito para desmentir las falsedades mediante el uso de datos. Se trata de un fenómeno actual que requiere ser investigado en diversos campos académicos.

Palabras clave: fact-checking; verificación; fake news; bulos; redes sociales; coronavirus; periodismo.

\begin{abstract}
Introduction: Fact-checking or data verification has become an increasingly popular journalistic practice. Without a doubt, it is a tool that has proven to be necessary to deny the fake news circulating on social networks, just as it has happened in the specific case of the coronavirus health crisis. Objectives: Analyze the characteristics of the false news denied by Newtral Media Audiovisual and determine its trend during the successive notices of extensions of the Alarm State. Methodology: 104 information referring to the coronavirus in Spain have been examined from March 14 to May 4, using the quantitative and qualitative analysis of the case study. Results: All the fake news have converged on different social networks, but the main channel for their diffusion has been WhatsApp, with text and audio being the formats that have been the most manipulated. On the other hand, the predominant theme of the hoaxes has been politics and the false attributions to institutions have managed to deceive citizens. Conclusions: The fact-checking confirms its success to deny falsehoods through the use of data. It is a current phenomenon that requires investigation in any academic fields.
\end{abstract}

Key words: fact-checking; check; fake news; hoaxes; social networks; coronavirus; journalism. 


\section{Introducción}

a crisis sanitaria del coronavirus ha estado plagada de falsedades. En España, el presidente del Gobierno, Pedro Sánchez, decretó el 14 de marzo, por segunda vez la historia de la democracia, el Estado de Alarma para la contención de la pandemia por la enfermedad del COVID-19. A partir de ese instante, el fenómeno en auge de las fake news, bulos o según recomienda Fundéu (2017), noticias falsas o falseadas, se han reproducido a gran velocidad a través de las redes sociales -especialmente por Facebook, Twitter y WhatsApp- ya que estas son el principal medio para su propagación (Lotero-Echevarri, Romero Rodríguez y Pérez-Rodríguez, 2018). Cierto es que las noticias falsas cuentan cada vez con mayor presencia en nuestra sociedad y se han convertido en una constante dentro de la profesión periodística (Alonso, 2019). Asimismo, la pérdida de centralidad de la fuente y la posibilidad de viralización de las noticias, disminuyen a menudo el interés por la veracidad de la información y las capacidades críticas para detectar lo que es falso (Fernández-García, 2017).

La discusión científica y social en torno al fenómeno de las fake news, y sus consecuencias en nuestra sociedad, llevó al Oxford Dictionary -considerado el más erudito y completo diccionario en lengua inglesa- y al Collins Dictionary a declarar este vocablo como palabra internacional del año en 2017, justo un año después de haber nominado con el mismo galardón al término posverdad (Rodríguez, 2017). Estas dos expresiones están sumamente ligadas entre sí, ya que las noticias falsas se refieren al elemento material que abunda en el contexto político y social al que hace referencia el término filosófico de posverdad. En este sentido, D'Ancona (2017) considera que la posverdad es la reacción de la sociedad ante la falsedad de los políticos. Este fenómeno es, de hecho, uno de los grandes objetos de estudio y uno de los grandes desafíos de la sociedad actual. La problemática de las noticias falsas, la desinformación, los bulos y el contenido sesgado que ubicamos en ese contexto en particular- es, según Aparici y García-Marín (2019), especialmente sensible cuando se sitúa en las coordenadas formadas por la institución política y las entidades mediáticas.

En suma, el Oxford Dictionary define el neologismo posverdad (post-truth en inglés) como "circunstancias en que los hechos objetivos influyen menos en la formación de la opinión pública, que los llamamientos a la emoción y a la creencia personal" (Oxford Dictionary, 2016). Por su parte, Murolo (2019) determina que esta circunstancia "se trata de una idea, un imaginario, un conjunto de representaciones sociales o sentidos ya incorporados por las audiencias y desde donde son posibles fake news que refieren a esa idea afirmándola o ampliándola".

Las noticias falsas no son un fenómeno nuevo. De hecho, la historia registrada de las guerras de desinformación ha acompañado al periodismo desde sus inicios, pero el siglo XXI, con el uso desmesurado de internet y las redes sociales, ha visto la utilización de la información como arma en una escala sin precedentes (Posetti \& Matthews, 2019). Sobre todo, desde 2016, año en el que Donald Trump fue elegido presidente de los Estados Unidos. Desde entonces, las fake news han estado presentes en el referéndum del Brexit, las elecciones francesas, el referéndum catalán, las elecciones generales de España del 28 de abril y en la actual crisis mundial del coronavirus. Llegados a este punto, se puede refutar que las noticias falsas no han estado exclusivamente ligadas al terreno político o a la verificación del discurso público (Amazeen, 2015; Salas, 2019) sino que se instauran en cualquier contexto analizando también la comunicación de crisis, desastres y emergencias (Conde-Vázquez, 2019; Mayo-Cubero, 2019), como es el caso de esta investigación.

Illades (2018) avanza que es una expresión a la que tendremos que acostumbrarnos, puesto que la realidad que estamos viviendo no es leal o sincera. El estudio de las noticias falsas se consolida y ello ofrece un asentamiento sobre su definición. Gelfert (2018) propone precisar que las noticias falsas son la presentación deliberada de reclamos falsos 0 engañosos como noticias, donde las afirmaciones son manipuladas "por diseño". En este "por diseño", Gelfert se refiere al papel fundamental que debe jugar el profesional de la información para resolver 0 verificar el contenido difamatorio. En este sentido, López-Borrull, Vives-Gràcia \& Badell (2018) constatan que las noticias falsas no se combaten con la censura sino precisamente con más noticias y más formación en fuentes de información. De este modo, se abren nuevas formas de innovar en las que el profesional de la información debe buscar la manera de aliarse con las redes sociales para atajar esta problemática.

Por ejemplo, durante la crisis del coronavirus, WhatsApp limitó el reenvío de mensajes con el objetivo de frenar el envío masivo de bulos. Facebook avisó a sus usuarios cuando estaban interactuando con contenidos falsos gracias al despliegue de algoritmos encargados de buscar informaciones falsas o engañosas entre sus 
anuncios de pagos, algo que también hizo Twitter, pero en su caso, detectando cuentas no oficiales. El periodismo de datos y su lucha por verificar las noticias ha dado paso al incipiente crecimiento del fact-checking, y con ello a la creación de plataformas fundadas en el entorno de un medio o de manera independiente que se encargan de que las noticias sean de calidad dando lugar a la aparición de un nuevo perfil experto en periodismo de datos como lo es el fact-checker. Además, según afirma Cristina Tardáguila, directora adjunta del International Fact-checking Network, en una entrevista concedida a El Mundo (2020), esta figura "siempre va a exponer y chequear bulos de los que tienen poder". En el caso de España, estos profesionales trabajan en diferentes plataformas independientes como Maldita.es y Efe Verifica.

Los datos recopilados por el Reuters Institute for the Study of Journalism atestiguan el éxito de este nuevo fenómeno (Graves \& Cherubini, 2016). El número de plataformas o "verificadores" de información ha crecido exponencialmente desde 2006, lo que les está permitiendo desmentir una marea de informaciones falsas en 78 países. Según el Reporters' lab de Duke University, en el año 2020 existen un total de 237 iniciativas fact-checking, y destacan un crecimiento de un $26 \%$ respecto al año anterior, cifra que seguirá aumentando (Stencel \& Luther, 2020).

No cabe duda de que el estudio y la implantación del fact-checking es toda una novedad, tanto en el mundo académico como en el profesional, por lo que es importante seguir investigando esta tendencia al alza que ofrecerá resultados de interés en otros ámbitos y contextos relacionados con el mundo de la comunicación, ya que es importante brindar a la ciudadanía una herramienta con la que poder distinguir una noticia real de una falsa y acabar así con las fake news. Por ello, como respuesta ante esta circunstancia, este artículo ofrece un análisis sobre Newtral Media Audiovisual, una startup de contenido audiovisual fundada en 2018 por la periodista Ana Pastor y adherida a la International Fact Cheking Network (IFCN), que durante la crisis sanitaria del coronavirus en España su tarea, además de ofrecer contenidos periodísticos, ha consistido mediante el uso de la verificación de datos, desmentir una gran cantidad de fake news que han sido difundidos en diferentes soportes y formatos.

Asimismo, se logra ofrecer una panorámica del trabajo que ha desarrollado esta plataforma de verificación de información, teniendo como objetivo analizar las características de los contenidos desmentidos durante la crisis sanitaria del coronavirus en España. Un factor que debe ser analizado en el entorno mediático de España y que servirá para ofrecer pautas, y resultados de interés para futuras investigaciones. No obstante, cabe aclarar que habrá que seguir analizando el fenómeno de las fake news surgidas durante esta pandemia puesto que, por limitaciones de tiempo solo se arrojan resultados desde el 14 de marzo hasta el inicio de la fase 0 de la desescalada. Además, al igual que ya han visto la luz estudios relacionados con las noticias falsas en redes sociales en España como fake news y coronavirus: detección de los principales actores y tendencias a través del análisis de las conversaciones en Twitter (Pérez-Dasilva, Meso-Ayerdi \& MendigurenGaldospín, 2020) y a nivel Internacional Impact of rumor sor misinformation on coronavirus disesase (COVI-19) in social media (Tasnim, Hossain \& Mazumder, 2020), se irán sumando otras como esta con el aporte del uso del recurso fact-checking, ya que tal y como exponen Nicole M. Krause, Isabelle Freiling, Becca Beets y Dominique Brossard (2010) en su reciente trabajo Fact-checking as risk communication: the multi layered risk of misinformation in times of COVID-19. Esta crisis nos ha ayudado a comprender la importancia de los verificadores de datos para acabar con la desinformación. Por ello, es necesario tomar como base algunos estudios previos para facilitar el trabajo y dotar de material a investigadores e investigadoras que aborden este tema con mayor profundidad en un futuro cercano.

\section{El fact-checking, la herramienta contra las fake} news

La innovación tecnológica, y con ello, la revolución de la verificación de datos (Graves, Brendan \& Reifler, 2015) ha llegado para quedarse. Desde hace aproximadamente una década, coincidiendo con el inicio de la crisis económica hacia el año 2008, los medios de comunicación han tenido que hacer frente a los cambios. Entre ellos, los relacionados con los hábitos de consumo de las audiencias, creando contenidos novedosos y de interés general, modificando el perfil de sus profesionales y buscando nuevos modelos de negocio para incrementar su creatividad y sus fuentes de ingresos (García, Chalezquer \& Martínez-Costa, 2016).

Durante esa etapa, con el cometido de incrementar la audiencia y mejorar su producción en términos de rentabilidad, la generalidad de los medios de comunicación comenzó a implantar estrategias de convergencia que se materializaron en una reducción de costes y en un cambio en el modelo o estructura de trabajo en las redacciones (López García \& Pereira, 2010). Aunque la crisis de la 
industria periodística junto con la publicitaria, profesional y empresarial haya provocado un cambio sustancial en la manera de consumir y producir las noticias, las empresas periodísticas continúan adaptándose a los nuevos tiempos en los que la tecnología cobra cada vez un mayor protagonismo (Ufarte-Ruiz, Peralta-García \& MurciaVerdú, 2018). De esta forma, internet, las redes sociales y los nuevos dispositivos han supuesto una revolución para la comunicación y la conexión entre personas (Vizoso, López-García \& Pereira-Fariña, 2018).

Sin embargo, doce años después, España se enfrenta no solo a una crisis sanitaria sino también a otra económica que ha afectado a todos los sectores, incluidos al de los medios de comunicación. Igualmente, el uso desmesurado de estos canales, los cuales son también portales de distribución de la información, ha provocado que las noticias pierdan veracidad debido a la sobreinformación, un hecho que manipula la realidad.

En esa búsqueda de calidad ha emergido con fuerza el periodismo de verificación de datos, también conocido como fact-checking, que da respuesta al fenómeno de la desinformación (Rodríguez, 2020) y sirve, al mismo tiempo, como herramienta para paliar el impacto de las noticias falsas en los medios o diferentes plataformas que hacen uso de este recurso que está en pleno apogeo. Ufarte-Ruiz et al. (2018) lo definen como "una operación que aplica técnicas del periodismo de datos para desenmascarar los errores, ambigüedades, mentiras, falta de rigor 0 inexactitudes de algunos contenidos publicados en los medios de comunicación". A partir del análisis de fuentes y otras técnicas, la práctica de verificación de datos, gracias a las herramientas tecnológicas, logran mediante algoritmos o cruce de datos, que el discurso periodístico sea veraz (López, Rodríguez \& Álvarez, 2016) y hacer un análisis crítico de lo que sucede (Zoomer, 2014, p. 6) para cumplir con su objetivo final: "informar con calidad al público" (Amazeen, 2015). Del mismo modo, los investigadores Álvarez \& López (2016) determinan que "el fact-checking aparece como una técnica que puede ayudar a combatir esos sesgos sensacionalistas".

Los proyectos fact-checking han irrumpido con fuerza en los últimos años (Spivak, 2011) expandiéndose tanto a nivel nacional como internacional, a pesar de que la labor de confirmar y comprobar hechos existe desde el inicio del periodismo (Ufarte-Ruiz et al., 2018). La primera iniciativa fact-checking nació en Estados Unidos y recibió el nombre de Spinsanity, a la que le siguieron otras como FackCheck.org, que surgió en 2003 en la Universidad de
Pensilvania. Tal ha sido su desarrollo que en España la implantación del fact-checking o verificación de datos se dejó sentir primero en plataformas independientes como Mala Prensa (2004) y poco después se abrió camino en varios medios y agencias de comunicación que dentro de sus departamentos han fundado sus propias unidades de verificación (tabla 1).

En este escenario, también ha surgido un nuevo perfil profesional para responder con éxito a los nuevos usos en relación con el consumo de la información (Armendáriz, 2015 , p. 154). Se trata de los fact-checkers, un equipo de profesionales expertos en periodismo de datos, o big data, que enrolan tres papeles diferentes: reporteros, activistas y expertos (Graves \& Cherubini, 2016, p. 12). En la búsqueda de la información veraz (López-García, Rodríguez-Vázquez \& Pereira-Fariña, 2017) los factcheckers se han apoyado en las redes sociales e internet, las cuales se han convertido en herramientas básicas de su trabajo diario, además de otras bases de datos en abierto, para interpretar y extraer datos que les permita verificar el hecho noticioso (Vizoso et al., 2018). La labor que desempeña este perfil profesional ha de ser tenido en cuenta puesto que su trabajo resulta primordial a la hora de detectar informaciones falsas. Ha podido comprobarse que en tiempo récord han logrado desmentir las falsedades que han recorrido las redes sociales durante la pandemia del coronavirus por lo que resulta interesante investigar y conocer el proceso de verificación que han llevado a cabo.

En este contexto de innovación y avance tecnológico, cada vez son más los investigadores e investigadoras que se centran en el estudio del fact-checking, una herramienta que está en pleno apogeo a nivel mundial. Aquellos más recientes ofrecen un estudio más macro o general sobre el asentamiento de este fenómeno en medios de comunicación y agencias o plataformas independientes (López et al., 2016; Magallón-Rosa, 2018; Ufarte-Ruiz et al., 2019; Palau-Sampio, 2018) los retos y dilemas que plantea su implantación en las redacciones (Rodríguez, 2020); la verificación del discurso en el entorno político (Mazaira-Castro, RúasAraújo \& Puentes-Rivera, 2019; Nyhan, Porter, Reifler \& Wood, 2019), y entre muchos otros, las habilidades tecnológicas del fact-checker en su compromiso con la calidad periodística (Graves \& Cherubini, 2016; Vizoso et al,. 2018). Sin duda, la proliferación de los proyectos de verificación de datos en el mundo académico y laboral demuestra la eficacia de la verificación de datos para combatir la desinformación más allá de los discursos políticos y la crisis sanitaria o económica. 
Tabla 1. Unidades fact-checking en España.

\begin{tabular}{|l|l|l|}
\hline \multicolumn{1}{|c|}{ Año } & \multicolumn{1}{|c|}{ Medio } & \multicolumn{1}{|c|}{ Tipo de proyecto } \\
\hline 2004 & Malaprensa (Josu Mezo) & Independiente \\
\hline 2006 & $\begin{array}{l}\text { Maldita Hemeroteca } \\
\text { (Clara Jiménez y Julio } \\
\text { Montes) }\end{array}$ & Independiente \\
\hline 2013 & $\begin{array}{l}\text { Maldito Bulo (Clara } \\
\text { Jiménez y Julio Montes) }\end{array}$ & Independiente \\
\hline 2015 & $\begin{array}{l}\text { La Chistera (El } \\
\text { Confidencial) }\end{array}$ & Depende del medio \\
\hline 2016 & $\begin{array}{l}\text { Verdad o Mentira } \\
\text { (Periodista digital) }\end{array}$ & Depende del medio \\
\hline 2017 & $\begin{array}{l}\text { El Objetivo (La Sexta) El } \\
\text { Cazabulos (eldiario.es) } \\
\text { Hechos (El País) }\end{array}$ & Depende del medio \\
\hline 2018 & $\begin{array}{l}\text { Newtral Media } \\
\text { Audiovisual (Ana Pastor) }\end{array}$ & Independiente \\
\hline 2019 & Efe Verifica (Agencia Efe) & Depende de la agencia \\
\hline
\end{tabular}

Fuente: elaboración propia.

\section{Metodología}

Este análisis en concreto ha seleccionado como objeto de estudio la startup y plataforma fact-checking independiente constituida por Ana Pastor, Newtral Media Audiovisual, por ser una de las adheridas a la International Fact-checking Network (IFCN). Se trata de una unidad del Instituto Pounter que nació en septiembre de 2015, comprometidos con la excelencia y el impulso de buenas prácticas en la verificación de noticias falsas, y que actualmente cuenta con 79 firmantes en todo el mundo. Ha sido seleccionada por ser la que más seguidores cuenta en sus redes sociales, por lo que su impacto en la sociedad es mucho mayor que el resto de las plataformas independientes del país. Por lo tanto, esta iniciativa factchecking, al igual que Maldita.es y Efe Verifica, cumple con los cinco principios básicos para poder estar inscritos en la IFCN y que se detallan a continuación:

1. Compromiso con la imparcialidad y la equidad.

2. Compromiso con la transparencia de las fuentes.

3. Compromiso con la transparencia de la financiación y la organización.

4. Compromiso con la transparencia de la metodología.

5. Compromiso con las correcciones abiertas y honestas.

Desde 2018, Newtral Media Audiovisual se encarga de la producción de programas de televisión y nuevas narrativas en redes sociales y la innovación en periodismoa través de la verificación de datos. Además, recientemente el equipo ha puesto en marcha una línea de investigación basada en los protocolos de inteligencia artificial. Durante la crisis sanitaria del coronavirus, en el caso concreto de España, ha jugado un papel fundamental desmontando los bulos que han recorrido las redes sociales. Para su detección y su posterior verificación habilitó el número +34 682589664 para que los ciudadanos les enviasen las posibles noticias falsas que se estaban haciendo virales en forma de cadena vía WhatsApp o circulando por más de una red social (Twitter, Facebook, etc). También ha hecho uso de su canal de Telegram, Newtral. es, para publicar cada día las principales verificaciones de bulos y todas las piezas explicativas de newtral.es vinculadas a los asuntos nacionales e internacionales. Sin embargo, cabe destacar que esta investigación se ha centrado únicamente en aquellas fake news que tenían una vinculación directa con España pudiendo así acotar nuestro objeto de estudio. Todas ellas han sido desmontadas por el equipo de profesionales de Newtral Media Audiovisual, un total de 71 personas, que está formado por periodistas, ingenieros/as, investigadores/ as, programadores/as, productores/as, realizadores/as, grafistas y documentalistas. 
En su página web, con los primeros brotes y rumores sobre los casos de coronavirus en China, crearon una sección específica sobre Coronavirus y una zona de verificación que lleva directamente a los fakes así como a los fact-checks, donde contrastan y verifican los discursos de los políticos a diario. Este último apartado también ofrece la posibilidad de ser analizado en un futuro, cuando el número de la muestra aumente con el fin del Estado de Alarma o con un posible rebrote de la enfermedad, pudiendo de este modo comparar los diferentes contenidos y tipos de manipulación en tiempos diversos o escalonados como es este caso.

En este trabajo, que combina las técnicas cuantitativa y cualitativa del estudio de caso, se pretenden analizar los aspectos formales de las noticias falsas o bulos que se han publicado durante el Estado de Alarma en España motivado por la crisis sanitaria por coronavirus, así como describir los procesos de verificación que emplea Newtral para combatir la problemática de la desinformación y la manipulación informativa. De igual modo, vinculado con el primer aspecto, quiere conocerse la tendencia de los bulos durante las diferentes prórrogas del Estado de Alarma hasta el inicio de la desescalada o también conocida como la etapa de preparación hacia la "nueva normalidad". Para ello, se han determinado cuatro periodos, más concretamente los instaurados por el Gobierno español. Se han establecido según los avisos de nuevas moratorias por parte del presidente Pedro Sánchez en sus sucesivas comparecencias, y que se dividen de la siguiente manera:

- 14 de marzo-27 de marzo.

- 28 de marzo-10 de abril.

- 11 de abril-26 de abril.

- 27 de abril-4 de mayo.

Por lo tanto, estos objetivos generales desencadenan las siguientes preguntas de investigación, que tal y como se ha detallado, se busca también conocer la propensión de los bulos durante diferentes fechas:

P1. ¿Cuál ha sido la temática predominante de las fake news desde el inicio del Estado de Alarma hasta la fase 0 de desescalada?

P2. ¿Qué formato ha prevalecido en la mayoría de las informaciones falsas?

P3. ¿Cuáles han sido los canales a través los cuales las fake news se han vuelto virales?

P4. ¿Qué firmas o a quién/es se les ha atribuido esas falsas informaciones con el fin de manipular a la sociedad?

El marco temporal establecido es desde el 14 de marzo, fecha en la que el Gobierno central decretó el Estado de Alarma, hasta el 4 de mayo, cuando finaliza el periodo de confinamiento y comienza la fase 0 del proceso de desescalada con las primeras salidas a la calle y la apertura de pequeños comercios. Es así un periodo suficientemente largo que nos permite recoger una muestra adecuada de desinformaciones, aunque no definitivas debido a las sucesivas prórrogas de Estado de Alarma. Asimismo, es importante subrayar que el número de la muestra se determina que es los bastante amplia puesto que se ha comparado con investigaciones realizadas anteriormente, que nada tienen que ver con este tema de actualidad, pero sí con el análisis de fake news en los discursos políticos o campañas electorales (Coromina \& Padilla, 2018; Vizoso y López, 2019), y puede señalarse que esta ofrece un número alto de piezas con una durabilidad más estable a lo largo de las semanas.

Para el análisis de las características formales de las noticias falsas o bulos, se ha elaborado una ficha de obtención de datos formada por cuatro indicadores la cual se ha diseñado una vez formuladas las preguntas de investigación. Este instrumento de recogida fue aplicado a una muestra de 104 informaciones relacionadas con la crisis sanitaria en España por el COVID-19.

En primer lugar, se comprobará el canal a través del cual se han propagado estos bulos (Facebook, Twitter, WhatsApp u otros), también cuál es su formato (texto, vídeo, audio, imagen u otros), quién firma o a quién/es les ha sido atribuidas estas informaciones falsas (una institución, asociación, grupo político, anónimo, medio de comunicación u otros) y finalmente, cuál es la temática que predomina en el conjunto de la muestra seleccionada (Sanidad, Política, Sociedad u otros). Esta tabla se ha completado, en un primer momento, en base al análisis de contenido web (Herring, 2010), que contempla la inclusión de elementos propios de internet, como son los enlaces y elementos multimedia y complementa el análisis de contenido tradicional (Bardin, 1977; Krippendorf, 2004). Es importante mencionar que todos estos datos han sido obtenidos de la propia página web de Newtral Media Audiovisual y posteriormente interpretados gracias al programa estadístico SPSS (tabla 2).

Igualmente, para conformar la muestra, se utilizaron los siguientes criterios de inclusión:

- La información falsa analizada debía haber sido previamente cotejada por los profesionales de la información.

- Las noticias y bulos seleccionados debían tener cierta trascendencia mediática y relevancia en las redes sociales (o mayor impacto).

En último lugar, es de especial relevancia apuntar también que Newtral Media Audiovisual sigue diferentes procesos de verificación en función de la veracidad de la declaración. Este hecho se contempla también en la 
investigación realizada por Ángel Vizoso y Xosé López García (2019), Newtral y Comprobado: experiencias de fact-checking durante la campaña electoral de las Elecciones Generales en España:

1. Verdadero. La noticia es completamente veraz por lo que es innecesario aportar información adicional.

2. Verdad a medias. Una parte de la información es correcta y cierta, pero en este caso en concreto la noticia necesitaría una aclaración.

3. Engañoso. La información combina datos correctos e incorrectos. En cierto modo presenta imprecisiones 0 falsedades que deben ser contrastadas.

4. Falso. La información es completamente falsa y le acompañan diferentes formatos tales como: vídeos, imágenes, audios, etc.

Tras la selección y posterior análisis de las piezas que forman parte de nuestro objeto de estudio, se ha comprobado que un total de 103 noticias falsas que han sido previamente desmentidas por esta plataforma, pertenecen a la cuarta categoría, excepto 1 que se integra en la tercera. Es decir, en el primer caso todas las afirmaciones son falsas, sin embargo, en el segundo hay imprecisiones que merecen ser también contrastadas. Además, antes de hacer público este resultado el fact ha tenido que pasar por tres filtros: el periodista, el equipo fact-checking y dirección (imagen 1).

Tabla 2. Ficha de datos a utilizar.

\begin{tabular}{|l|l|l|l|}
\hline \multicolumn{3}{|c|}{ Ficha de datos } \\
\hline I. Temática & $\begin{array}{l}\text { Sanidad } \\
\text { Política } \\
\text { Educación } \\
\text { Sociedad } \\
\text { Otros }\end{array}$ & III. Canal de distribución & $\begin{array}{l}\text { Facebook } \\
\text { Twitter } \\
\text { WhatsApp } \\
\text { Otros }\end{array}$ \\
\hline II. Formato & $\begin{array}{l}\text { Texto } \\
\text { Vídeo } \\
\text { Audio } \\
\text { Foto } \\
\text { Otros }\end{array}$ & IV. Atribución de Autoría & $\begin{array}{l}\text { Institución } \\
\text { Asociación } \\
\text { Grupo político } \\
\text { Medio de comunicación } \\
\text { Otros }\end{array}$ \\
\hline
\end{tabular}

Fuente: elaboración propia.

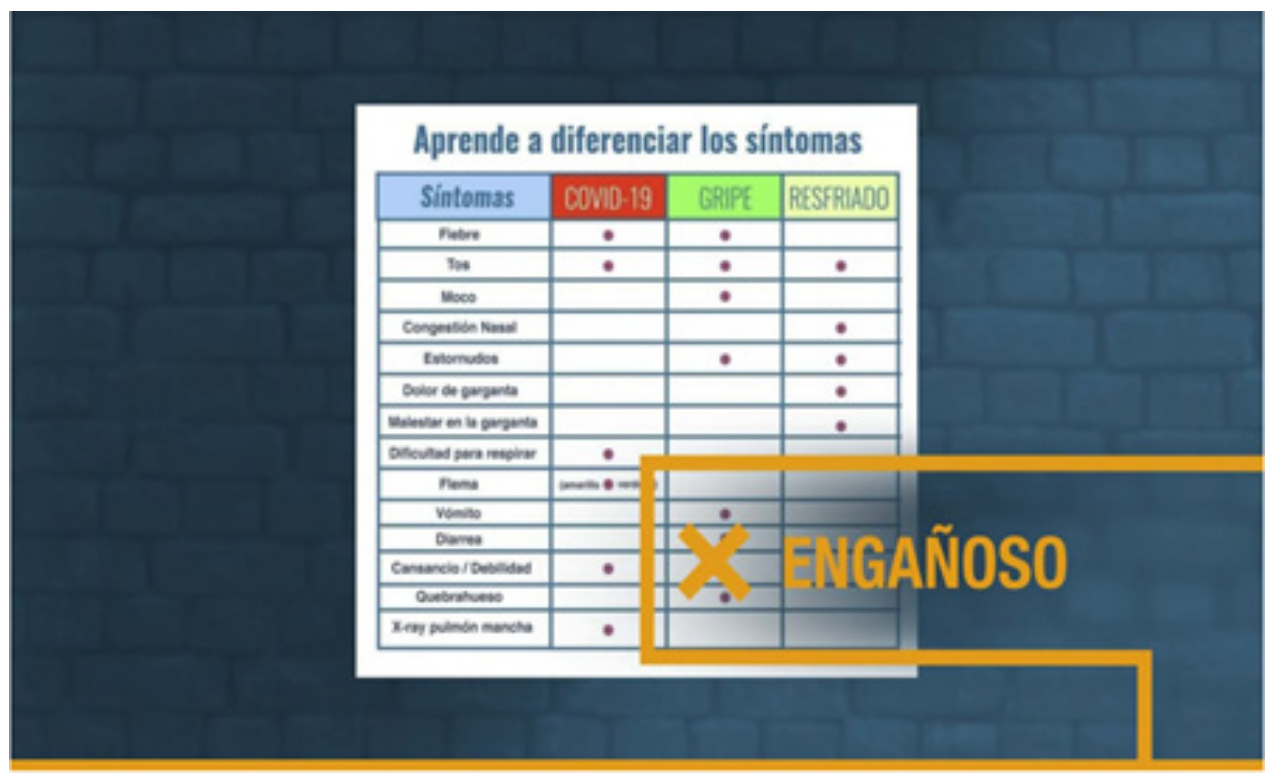

Imagen 1. Captura de una tabla de información que se hizo viral en redes. Fuente: Newtral Media Audiovisual. 


\section{Resultados}

Con todos los datos que nos proporciona Newtral Media Audiovisual hemos podido analizar, identificando previamente todas las fake news, los siguientes aspectos que han logrado dar respuesta a los objetivos planteados haciendo uso de los cuatro indicadores establecidos.

En primer lugar, se aprecia que la temática predominante en la mayoría de las noticias falsas es la Política, siendo un $48 \%$ del total. La segunda posición la ocupa la temática de Sanidad con el $26 \%$, seguida de Sociedad (14\%). Por último, con el porcentaje más bajo, un $12 \%$ del total, se registra la temática Educación.

Haciendo un recorrido por el periodo de tiempo seleccionado para esta investigación, se puede afirmar que entre el 14 y el 27 de marzo las fake news desmentidas versan en su mayoría sobre Política (47\%), seguidas de las que tratan sobre Educación (11\%) que se encuentra prácticamente a la par que Sanidad (10\%), y en el último puesto Sociedad con un $7 \%$. Posteriormente, entre el 28 de marzo y el 10 de abril, cabe destacar que la temática de Educación no aparece entre las informaciones analizadas. Sanidad se sitúa a la cabeza con un $33 \%$, seguida de Política (22\%) y Sociedad (3\%). Lo mismo ocurre en el periodo que abarca desde el 11 al 26 de abril, que no aparece registrada la categoría de Educación a la que se le suma la de Sanidad. La que predomina en este caso es Política, con un $68 \%$, seguida de Sociedad (31\%). Finalmente, entre el 27 de abril y el 4 de mayo la temática de la mayoría de las informaciones desmentidas fue la de Sociedad (38\%), seguida por Sanidad (28\%) y Política (23\%) (gráfico 1).

Otro de los aspectos analizados ha sido el de los formatos de estas informaciones falsas. El más utilizado ha sido indudablemente el texto, con un $42 \%$ del total. El segundo y tercer lugar lo ocupan las fotos (19\%) y vídeos $(18 \%)$ respectivamente, seguidos de la categoría "otros", que en su totalidad son enlaces y tablas, un $14 \%$. Finalmente, el formato menos empleado ha sido el audio (7\%).

Desglosando estos datos por fechas, entre el $14 \mathrm{y}$ el 27 de marzo, el texto (46\%) aparece como el formato más utilizado. Le siguen a cierta distancia las fotos con un $20 \%$. La categoría "otros" (11\%) empata con la de vídeo (11\%), y tras estas aparece el audio con un $9 \%$. El periodo que va desde el 28 de marzo al 10 de abril está protagonizado nuevamente por el texto que aparece en un $50 \%$ de los bulos desmentidos. Muy por detrás está el vídeo con un $25 \%$. La categoría foto $(9 \%)$ cuenta con el mismo porcentaje que la de "otros" ( $9 \%)$, y el último puesto lo ocupa el audio (6\%). Entre el 11 y el 26 de abril se produce un cambio, ya que los vídeos toman el papel protagonista (28\%), seguidos por las categorías de texto $(23 \%)$ y foto $(23 \%)$. En el grupo «otros» se registran un $19 \%$ de las informaciones falsas analizadas. Por último, aparece el formato de audio (4\%). Entre el 27 de abril y el 4 de mayo, el formato más utilizado vuelve a ser el texto (33\%). A continuación, la categoría "otros" (25\%), seguida por muy poco de las fotos (23\%). En último lugar y con el mismo porcentaje se sitúan el audio y el vídeo (8\%) (gráfico 2).

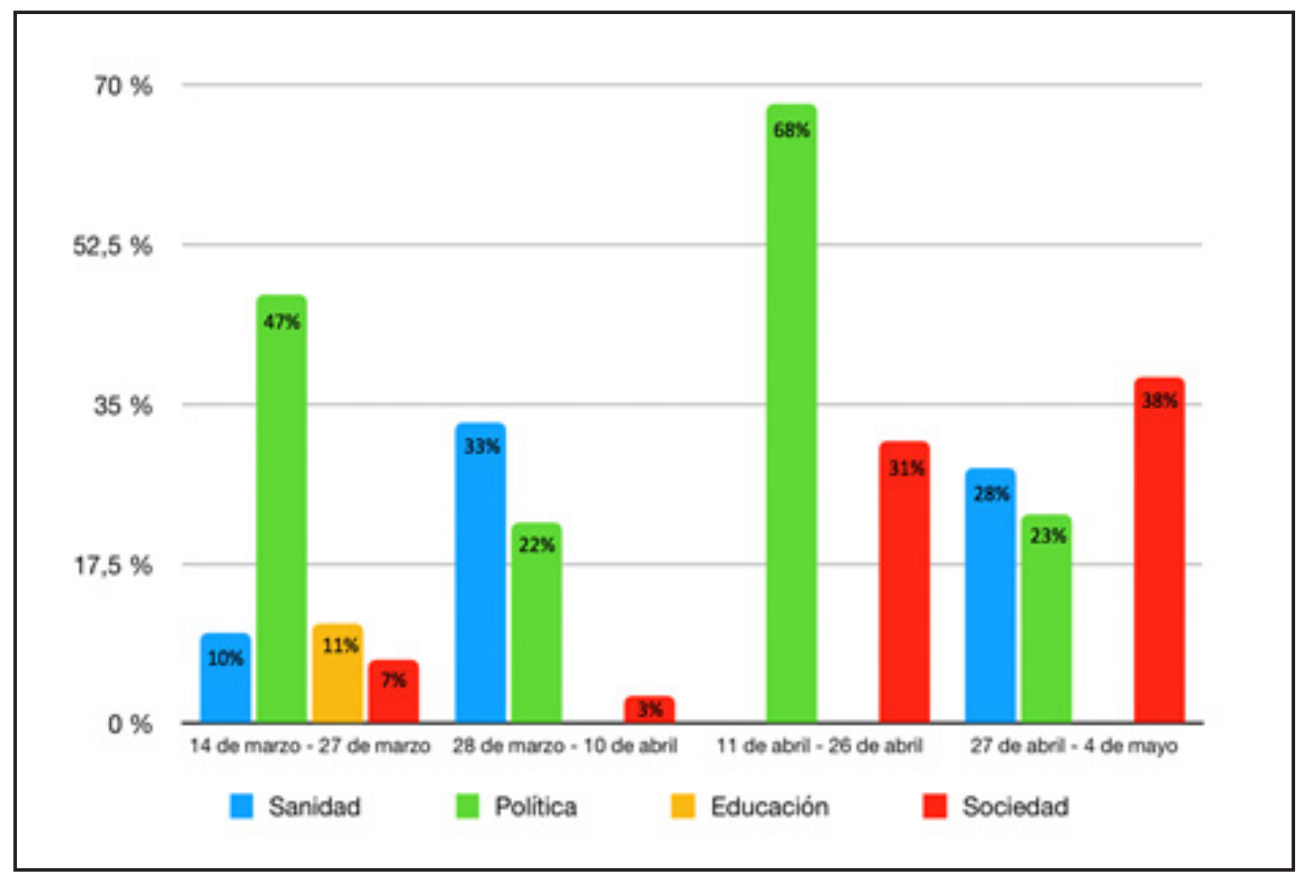

Gráfico 1. Temática de las noticias falsas desmentidas. Fuente: elaboración propia. 


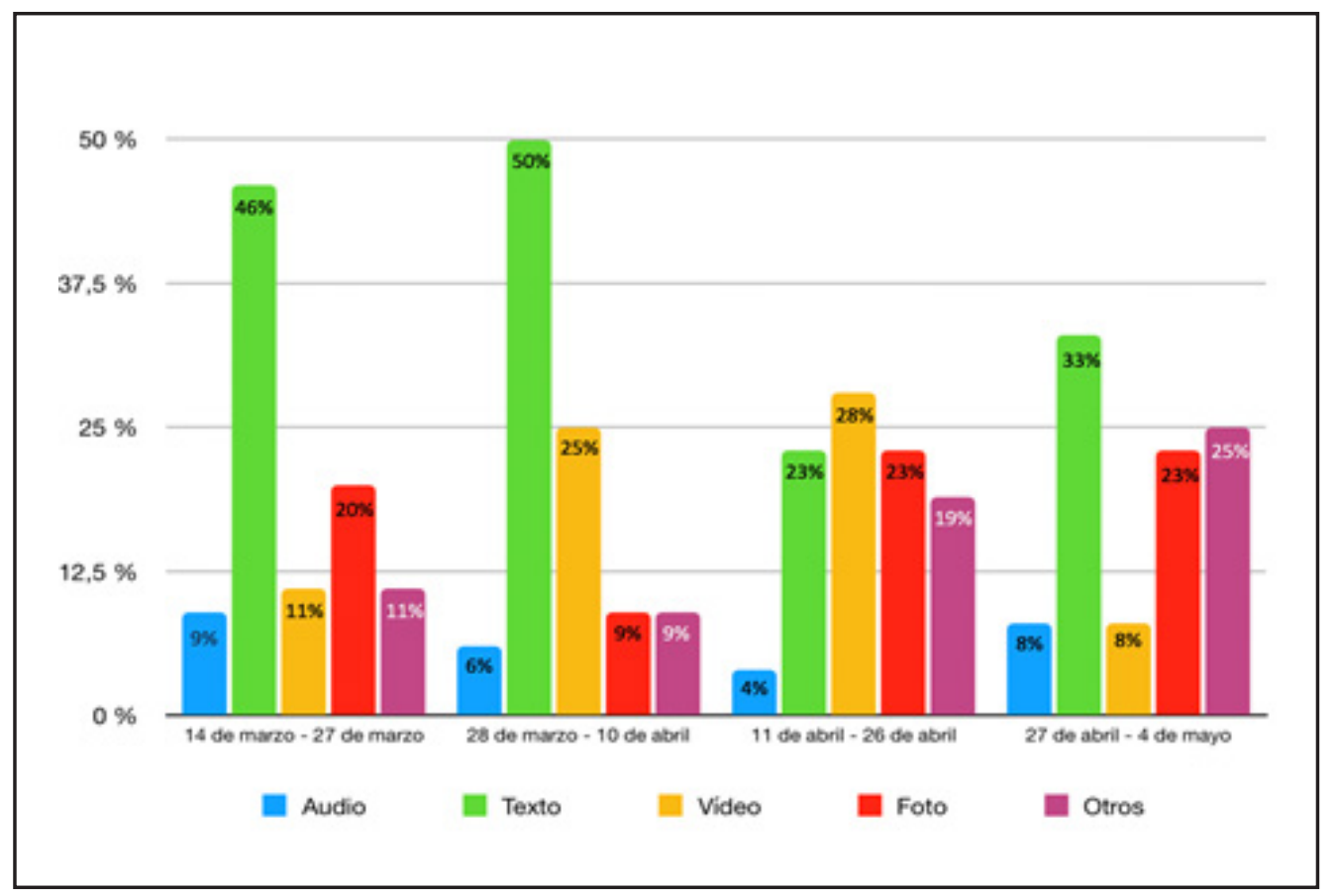

Gráfico 2. Formatos de los bulos desmentidos. Fuente: elaboración propia.

Respecto al canal de distribución, cabe destacar que WhatsApp ha sido la red social más usada para difundir los bulos (43\%), seguida de Twitter (27\%) y Facebook (23\%). Sobre todo, los textos acompañados de audios e imágenes han recorrido esta primera aplicación de mensajería mientras que los textos acompañados por vídeos han sido difundidos con una mayor frecuencia a través de Twitter y Facebook. En cuanto "otros" (7\%) es importante mencionar que dentro de esta categoría se encuentran correos electrónicos (4 noticias), YouTube (2 noticias) e Instagram (2 noticias) que siendo una minoría se decidió englobarlos de manera conjunta.

En lo referente a los cuatro periodos establecidos se puede confirmar que la red social más utilizada desde el inicio del decreto del Estado de Alarma, del 14 al 27 de marzo, fue WhatsApp (52\%), seguida de Twitter (26\%), Facebook (16\%) y "otros" (3\%). En lo referido a este último aspecto, se constata que aquí entran, sobre todo, aquellos fraudes denominados Pishing, o más conocidos como falsas ofertas o estafas en internet sin ningún remitente, que circulan por correo electrónico o por la red, y que han sido atribuidas a Mercadona, CaixaBank, Correos, Netflix y campañas de la ONU que tenían como objetivo hackear cuentas. Estos acabaron convirtiéndose en virales, sobre todo por WhatsApp y Facebook.

Asimismo, como puede observarse, el uso de estos canales mantiene la misma lógica y orden que los resultados globales que se han arrojado al comienzo de este apartado, en lo referido canal de distribución. Este hecho cambia considerablemente en la segunda etapa, la comprendida entre el 28 de marzo hasta el 10 de abril, puesto que WhatsApp se sitúa en tercer lugar con un $9 \%$ mientras que, a la cabeza, y con los mismos datos, un $27 \%$ para ser más exactos, se encuentran Facebook y Twitter mientras que aumenta en un $3 \%$ otro tipo de canales de distribución. Por consiguiente, del 11 al 26 de abril, Facebook vuelve a repuntar su uso (33\%) al igual que lo hizo WhatsApp (33\%) mientras que Twitter baja en un $2 \%$ respecto al anterior periodo. En su caso, la categoría "otros" vuelve a aumentar en un $2 \%$. En general, puede concluirse que la tendencia general del uso de canales es la que se refleja en el gráfico general y lo ha hecho desde el inicio de la preparación de la fase de desescalada, el 27 de abril, hasta el inicio de la fase cero con WhatsApp en el primer lugar del ranking, seguido de Twitter $(28 \%)$, pero con un empate entre Facebook (21\%) y otro tipo de canales (21\%) menos comunes durante la difusión de bulos durante la crisis del coronavirus en España (gráfico 3).

Para finalizar, otra de las cuestiones que se ha tenido en cuenta ha sido la atribución de autoría de los propios bulos. Un aspecto difícil de conocer y que en algunos casos la fuente de estos es totalmente desconocida $(18 \%)$. Nos obstante, nos ha permitido determinar que en un $31 \%$ de las fakes, situándose en primera posición de la clasificación de esta categoría, se atribuían a instituciones -ayuntamientos y otros organismos públicos-. En todos estos casos se trataba de un documento con el membrete de cada organismo lo que aportaba credibilidad al contenido. En segundo lugar, los grupos políticos (en la que también se incluyen los propios políticos) han 
acaparado los titulares en un $22 \%$ de los bulos seguido de otro tipo de autorías como asociaciones, supermercados, compañías telefónicas, etc. y que han ocupado, como en el resto de los componentes analizados, un porcentaje muy pequeño. Los centros sanitarios -hospitales y residencias- $(6 \%)$, junto con los medios de comunicación (7\%), han sido los menos perjudicados. Hay que matizar que en el caso concreto de los medios (La Razón, Agencia Efe, El Mundo, Cadena Ser y La Voz de Galicia), sus páginas webs han sido manipuladas, más concretamente los titulares que son lo más llamativo de las noticias.

Haciendo una comparación con el gráfico general y con el análisis de los diferentes periodos, se demuestra también en esta ocasión que las instituciones $(38 \%)$ han sido protagonistas durante el primer periodo, del 14 al 27 de marzo, seguido de los grupos políticos (19\%). Puede percibirse también cómo los medios de comunicación y "otros" han empatado (9\%), y con un porcentaje muy bajo en el transcurso de las primeras semanas del Estado de Alarma, al igual que los centros de salud (7\%) (gráfico 4).

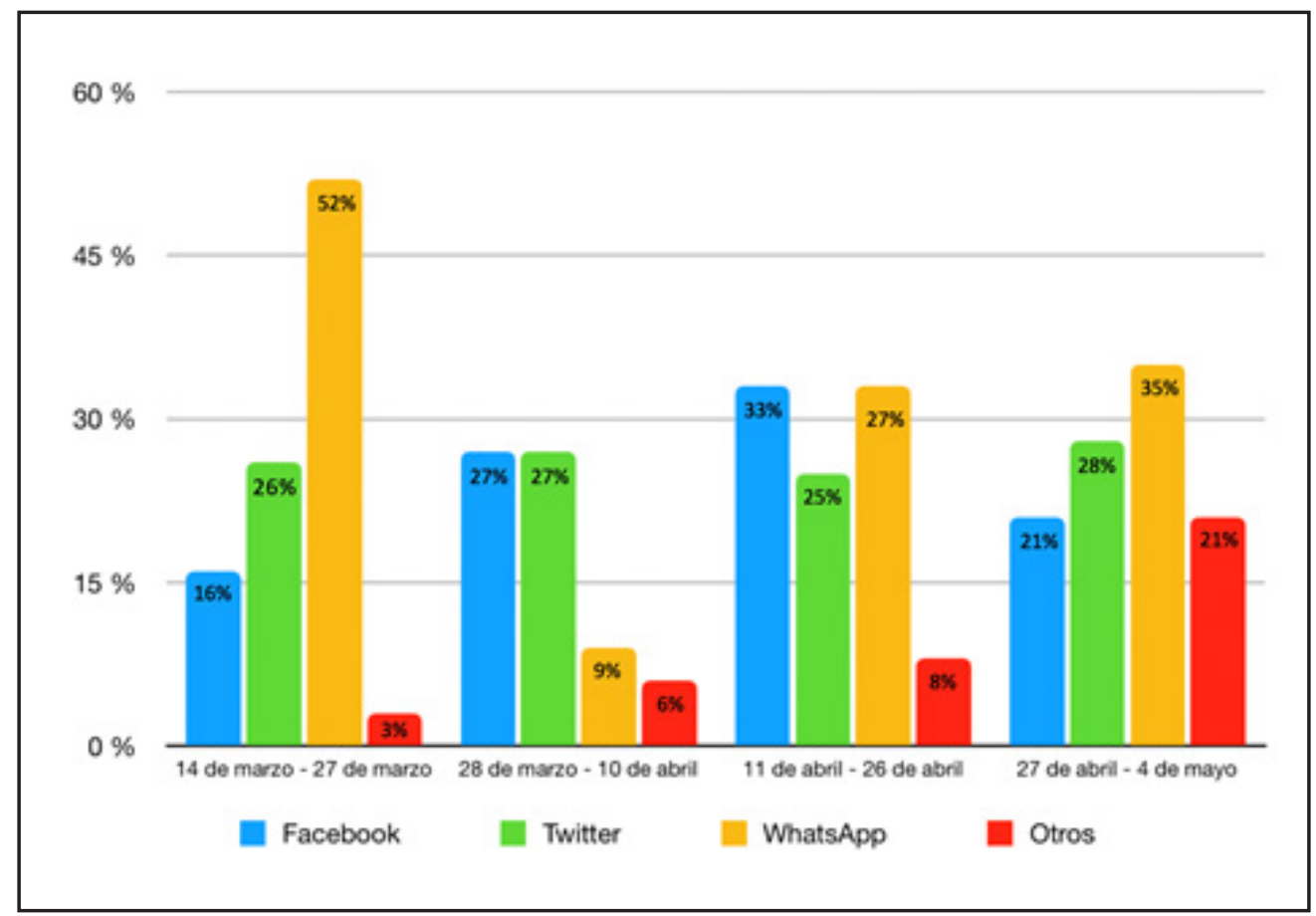

Gráfico 3. Canal de distribución de los bulos. Fuente: elaboración propia.

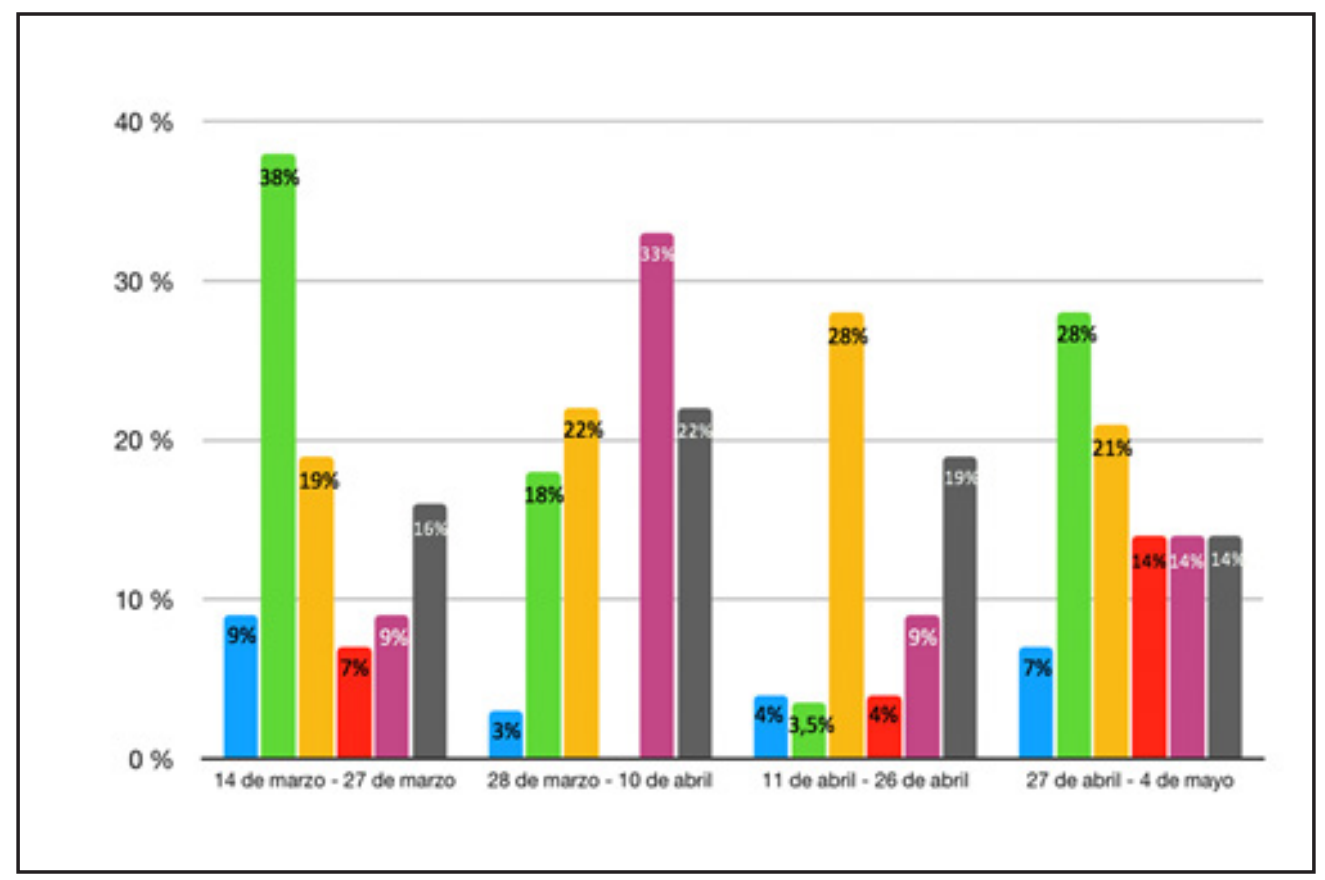

Gráfico 4. Atribución de autoría de los bulos. Fuente: elaboración propia. 
Se ha dejado para el final de esta primera etapa una mención a la atribución de autorías desconocidas (16\%). Teniendo una presencia bastante considerable durante la crisis del coronavirus, no se ha logrado conocer su procedencia. Desde el inicio de la pandemia hasta el final de nuestra muestra se trata, en la mayoría de los casos, de bulos relacionados con consejos para vencer al virus que han recorrido las redes, sobre todo por WhatsApp, lo que demuestra la poca fiabilidad de estas informaciones en las que ni siquiera citan una fuente oficial. Un aspecto básico que ha de tenerse en cuenta para saber si la noticia es veraz o falsa, y que Newtral Media Audiovisual ha logrado, acudiendo a ellas en el $100 \%$ todas las noticias falsas para ser posteriormente desmentidas. Además, como puede percibirse en las siguientes tres etapas su aumento ha ido in crescendo hasta alcanzar su pico más alto (33\%) entre el 28 de marzo y el 10 de abril. Mientras tanto, también la categoría "otros", a la que tal y como se ha apuntado, se refiere a cadenas de supermercados, compañías telefónicas, marcas de zapatillas, etc. mantiene una tendencia muy plana hasta el 4 de mayo llegando a ponerse en primera posición también del segundo rango de fechas. Igualmente, le sigue en segundo lugar las referidas a los grupos políticos $(22 \%)$, instituciones $(18 \%)$ y medios de comunicación $(3 \%)$. En este caso no se hace ninguna referencia a ningún centro de salud. Por otro lado, del 11 al 26 de abril, las autorías referidas a los grupos políticos (28\%) ocupan el primer puesto. No han tenido tanta presencia los centros de salud, medios de comunicación e instituciones que presentan unos datos muy similares y una diferencia del $24,5 \%$ con respecto al líder. Por último, del 27 de abril al 4 de mayo, la tendencia es muy similar a la de la primera fase situándose en primera posición las instituciones $(28 \%)$, grupos políticos $(21 \%)$, centros de salud (14\%) y medios de comunicación $(7 \%)$. Como último apunte, cabe aclarar que las informaciones desmentidas por Newtral Media Audiovisual no fueron elaboradas y difundidas por una autoría oficial.

\section{Discusión y conclusiones}

Esta investigación cuenta con un carácter novedoso y de rigurosa actualidad, puesto que pretende analizar el funcionamiento de la plataforma independiente de verificación Newtral Media Audiovisual entorno a las fake news surgidas en España a raíz de la crisis sanitaria por el coronavirus. Estos medios centrados en el factchecking han suscitado el interés de la comunidad investigadora en los últimos años, y esto, sumado al gran cambio en la sociedad a corto y largo plazo a causa de la pandemia por el COVID-19, abre un amplio abanico de posibilidades para futuras investigaciones.

Es cierto que este proyecto cuenta con un amplio margen de mejora, puesto que las fases de desescalada son diferentes en cada comunidad, por lo tanto, la continuidad de este artículo es totalmente pertinente y necesaria. De igual modo, un periodo de estudio más extenso permitiría ahondar en la evolución y la envergadura real de los bulos desmontados mediante las herramientas que emplea el fact-checking, en la actual crisis sanitaria, así como comprender de forma general los procesos y métodos en los medios de comunicación que tienen como objetivo la verificación de la información.

Se considera relevante de cara a un futuro análisis, conocer en profundidad el perfil profesional de los trabajadores de estos medios de comunicación, los fact-chekers, una figura en constante crecimiento. Este perfil periodístico tiene como cometido primordial aclarar todas aquellas informaciones que se realizan con la intencionalidad de manipular a la ciudadanía con informaciones falsas y erróneas. Con todos los datos y gracias a las herramientas de comprobación existentes en la actualidad, pueden desmontar cualquier falsedad acudiendo al germen de las noticias (Graves, 2016). No obstante, la reciente instauración y uso de la herramienta del fact-checking para detectar noticias falsas debe seguir siendo analizada en cualquier campo, puesto que surgirán nuevas problemáticas en el mundo actual y será necesaria seguir nutriendo con materiales como este a investigadores e investigadoras. Además, la bibliografía sobre este nuevo fenómeno sigue siendo escasa debido a su novedad por lo que es importante aportar trabajos recientes y de interés tanto para la comunidad científica como para la sociedad en general.

Por ello, la investigación realizada nos ha permitido dar respuesta a las preguntas de investigación planteadas confirmando a la vez que la muestra que recoge las 104 noticias falsas verificadas por la plataforma independiente Newtral Media Audiovisual es suficiente amplia y rica para analizar, gracias a las referencias facilitadas en su página web, cuatro aspectos diferenciados: temática, formato, canal y atribución de autoría. Asimismo, se puede corroborar que el factchecking se está convirtiendo en un término y en una herramienta cada vez más en boga, ya que permite verificar el grado de veracidad de la noticia haciendo uso de los datos, acabando así con las denominadas fake news. En la crisis del coronavirus, los grupos que trabajan sobre una vía de innovación en comunicación, como es el caso de esta plataforma independiente, han jugado un papel primordial para desmontar aquellos bulos 
con presencia en las redes sociales, convirtiéndose en referentes de la información periodística de calidad. De este modo, se ha podido determinar mediante dos vías, una con un estudio general y otra mediante la distinción de cuatro fases diferentes, lo siguiente:

En primer lugar, se ha constatado que la temática predominante de los bulos desmentidos por Newtral Media Audiovisual gira en torno a la Política, seguida de Sanidad, Sociedad y Educación. Además, ha sido con diferencia la más susceptible durante las semanas del 14 marzo al 27 de marzo; 11 de abril al 26 de abril y del 27 de abril al 4 de mayo. No es de extrañar puesto que los diferentes políticos han estado muy expuestos a las críticas por sus tomas de decisiones durante la pandemia del virus.

En segundo lugar, se ha afirmado que los bulos en formato de texto han sido los más abundantes en las diferentes etapas establecidas, así como en general, pero las fotos, audios y vídeos, han tenido igualmente una importante presencia en las redes sociales. Además, algunos de ellos han sido manipulados con membretes y firmas falsas pertenecientes a los diferentes organismos consiguiendo tergiversar la realidad. Porotro lado, todas las fakes news han navegado por diferentes redes sociales, pero la aplicación de mensajería WhatsApp ha sido, sin duda, la más utilizada para su propagación mientras que Twitter y Facebook se han colocado en segunda y tercera posición, respectivamente. Además, como bien es sabido WhatsApp es uno de los canales por excelencia que más usa la sociedad actual para estar conectados en cualquier momento y lugar para intercambiar mensajes, según el último informe arrojado por Hootsuit a principios de año. Por lo tanto, es también la más evidente para, en cadenas, crear y difundir noticias sin ningún criterio, sobre todo, textos acompañados de imágenes y audios. Por el contrario, en Facebook y Twitter los textos seguidos de vídeos han sido los protagonistas. Además, es también la que encabeza el ranking durante la primera, tercera y cuarta etapa que se han establecido para este estudio, lo que hace ver, al igual que en el caso de la temática, que es en el segundo periodo donde menos bulos se han desmentido, y en la que Facebook y Twitter han tenido una mayor relevancia para su difusión.

Aun así, tal y como puede comprobarse, cualquier red social ha servido para difamar el ejercicio de la profesión periodística, donde los profesionales ofrecen noticias veraces y contrastadas. Newtral Media Audiovisual ha recogido y desmentido cinco casos de cinco medios diferentes la manipulación de los titulares en sus páginas webs, pero es un porcentaje muy pequeño en comparación con las 99 informaciones restantes desmentidas por la plataforma y que en el $100 \%$ de los casos ha recurrido a la autoría, es decir, a la fuente oficial del bulo para saber el grado de veracidad de la noticia. Es cierto que este último aspecto, el referido a la atribución de autoría, ha sido un aspecto difícil de determinar y en la que en un $18 \%$ de las piezas seleccionadas se desconoce su origen, pero este hecho demuestra la importancia del papel que juegan los medios de comunicación para que la ciudadanía, en un momento tan delicado, estén adecuadamente informados. Mediante el análisis, se ha podido determinar, por lo tanto, que las instituciones han sido las más susceptible a la hora de crear los bulos, ya que sus constantes atribuciones a ellas así lo han demostrado. Además, con una tendencia que se ha mantenido a lo largo de las semanas menos en la del 11 al 26 de abril en el que también los grupos políticos han sido, en segundo lugar, la motivación para la creación de bulos durante la crisis del coronavirus en España.

\section{Referencias bibliográficas}

Alonso, M. (2019). Fake news: desinformación en la era de la sociedad de la información. Ámbitos. Revista Internacional de Comunicación, 45, 29-52. https:// doi.org/10.12795/Ambitos.2019.i45.03

Álvarez, L., \& López, X. (2016). El fact checking como herramienta de combate contra el sensacionalismo. In Almuiña, C., Martín de la Guardia, R. \& Pelaz, José-Vidal (Eds.), Sensacionalismo y amarillismo en la historia de la comunicación (pp. 215-228). Madrid, España: Fragua.

Amazeen, M. A. (2015). Revisiting the epistemology of fact-checking. Critical Review, 27(1), 1-22. https:// doi.org/10.1080/08913811.2014.993890

Aparici, R., \& García-Marín, D. (2019). La posverdad. Una cartografía de los medios, las redes y la política. Barcelona, España: Gedisa.

Armendáriz, E. (2015). El nuevo perfil del profesional de la comunicación y las relaciones públicas. Una visión desde la perspectiva del mercado. Revista Internacional de Relaciones Públicas, 5(9), 153178. https://doi.org/10.5783/RIRP-9-2015-09-153-178

Bardin, L. (1977). Análise de conteúdo. Lisboa, Portugal: Edições 70.

Collins Dictionary. (2017, noviembre 2). Collins 2017 Word of the Year Shortlist. Recuperado de: https://n9.cl/hp11 
Conde-Vázquez, E. (2019). Comunicación de crisis: fake news y seguimiento informativo en la ola de incendios de Galicia en octubre de 2017. Revista Española de Comunicación en Salud, suplemento 1, 107114. Recuperado de: https://n9.cl/1gemc

Cubero, M. M. (2019). Uso de las redes sociales en la cobertura periodística de crisis, desastres y emergencias en España. Revista Española de Comunicación en Salud, suplemento 1, 43-54. Recuperado de: https://n9.cl/sqvl

D'Ancona, M. (2017). Post-truth: The new war on truth and how to fight back. London, United Kingdom: Random House.

El Mundo (2020). Los fact-checkers siempre van a exponer y chequear bulos de los que tienen el poder. Recuperado de: https://n9.cl/76e6i

Fernández-García, N. (2017). Fake news: una oportunidad para la alfabetización mediática. Nueva sociedad, (269), 66-77.

Fundéu (2017, noviembre 28). Noticias falsas o falseadas, mejor que fake news. Recuperado de: https://n9.cl/x9ch

García Avilés, J., Chalezquer, C. S., \& del Pilar MartínezCosta, M. (2016). Innovación y desarrollo de los cibermedios en España. Navarra, España: Ediciones Universidad de Navarra.

Gelfert, A. (2018). Fake news: A definition. Informal Logic, 38(1), 84-117. https://doi.org/10.22329/ il.v38i1.5068

Graves, L., Brendan, N., \& Reifler, J. (2015). The Diffusion of Fact-checking. Understanding the growth of a journalistic innovation. United States: American Press Institute.

Graves, L. (2016). Anatomy of a Fact Check: Objective Practice and the Contested Epistemology of Fact Checking. Communication, Culture \& Critique, 10(3), 518-537.

Graves, L., \& Cherubini, F. (2016). The Rise of Factchecking Sites in Europe. Oxford, United Kingdom: University of Oxford. Recuperado de: https://n9.cl/557v
Herring, S. (2010). Web content analysis: Expanding the paradigm. In J. Hunsinger; L. Klastrup \& M. Allen (Eds.), International handbook of internet research (pp. 233-249). New York, United States: Springer Verlag. https://doi.org/10.1007/978-1-4020-9789-8_14

Hootsuit. (2020). Global reports. Recuperado de: https:// hootsuite.com/es/pages/digital-2020

Illades, E. (2018). Fake news: la nueva realidad. Barcelona, España: Grijalbo.

Krause, N. M., Freiling, I., Beets, B., \& Brossard, D. (2020). Fact-checking as risk communication: the multilayered risk of misinformation in times of COVID-19. Journal of Risk Research, 1-8. https://doi.org/10.1 080/13669877.2020.1756385

Krippendorf, K. (2004). Content analysis: An introduction to its methodology. Thousand Oaks, United States: Sage.

López-Borrull, A., Vives-Gràcia, J., \& Badell, J. (2018). Fake news, ¿amenaza u oportunidad para los profesionales de la información y la documentación?. El profesional de la información, 27(6), 13461356. https://doi.org/10.3145/epi.2018.nov.17

López García, X., \& Pereira, X. (2010). Convergencia digital: Reconfiguración de los medios de comunicación en España. Santiago de Compostela, España: Universidad Santiago de Compostela.

López-García, X., Rodríguez-Vázquez, A. I., \& PereiraFariña, X. (2017). Competencias tecnológicas y nuevos perfiles profesionales: desafíos del periodismo actual. Comunicar: Revista científica iberoamericana de comunicación y educación, 25(53), 81-90. https://doi.org/10.3916/C53-2017-08

López, X., Rodríguez, A. I., \& Álvarez., L. (2016). El fact checking como reclamo y como servicio en los cibermedios: Análisis de las experiencias de The Washington Post y The Guardian. Telos. Cuadernos de comunicación e innovación, 103, 74-83.

Lotero-Echeverri, G., Romero-Rodríguez, L. M., \& PérezRodríguez, M. A. (2018). Fact-checking vs. fake news: Periodismo de confirmación como recurso de la competencia mediática contra la desinformación. Index.comunicación, 8(2), 295-316. 
Magallón-Rosa, R. (2018). Nuevos formatos de verificación. El caso de Maldito Bulo en Twitter. Sfera Pública, 1(18), 41-65. Recuperado de: https:// n9.cl/1k4ex

Mazaira-Castro, A., Rúas-Araújo., J. \& Puentes-Rivera, I. (2019). Fact-checking en los debates electorales televisados de las elecciones generales de 2015 y 2016. Revista Latina de Comunicación Social, 74, 748-766. https://doi.org/10.4185/RLCS-20191355-38

Murolo, L. (2019). La posverdad es mentira. Un aporte conceptual sobre periodismo y fake news. In Aparici, R., \& García Marín, D. (Coords.), La posverdad. Una cartografía de los medios, las redes y la política. Barcelona, España: Gedisa.

Nyhan, B., Porter, E., Reifler, J., \& Wood, T. J. (2019). Taking fact-checks literally but not seriously? The effects of journalistic fact-checking on factual beliefs and candidate favorability. Political Behavior, 1-22. https://doi.org/10.1007/s11109-019-09528-x

Oxford Languages. (2016). Word of the Year 2016. Recuperado de: https://n9.cl/v6lw

Oxford Learner's Dictionaries. (2020). Definition of post-truth adjective from the Oxford Advanced Learner's Dictionary. Recuperado de: https:// n9.cl/bkjw

Palau-Sampio, D. (2018). Fact-checking and scrutiny of power. Supervision of public discourses in new media platforms from Latin America. Communication \& Society, 31(3), 347-365. https:// doi.org/10.15581/003.31.3.347-363

Pérez-Dasilva, J. Á., Meso-Ayerdi, K., \& MendigurenGaldospín, T. (2020). Fake news y coronavirus: detección de los principales actores y tendencias a través del análisis de las conversaciones en Twitter. El profesional de la información, 29(3), 1-22. https://doi.org/10.3145/epi.2020.may.08

Posetti, J., \& Matthews, A. (2019). Una Breve Guía de la Historia de las noticias falsas y la desinformación: Un Nuevo Módulo de Aprendizaje por ICFJ. International Centre for Journalists. Recuperado de: https://n9.cl/rvm0
Rodríguez, C. (2017). Fake news, palabra del año del Diccionario Oxford. El Mundo. Recuperado de: https://n9.cl/0dmr

Rodríguez, C. (2020). Una reflexión sobre la epistemología del fact-checking journalism: retos y dilemas. Revista de Comunicación, 19(1), 243-258. https:// doi.org/10.26441/RC19.1-2020-A14

Salas, C. (2019). La primera fake news de la historia. Historia y Comunicación Social, 24(2), 411-431.

Stencel, M. \& Luther, J. (2020). Update: 237 fact-checkers in nearly 80 countries... and counting. Reporters' Lab. Recuperado de: https://n9.cl/zghc

Spivak, C. (2011). The fact-checking explosion. American Journalism Review, 32(4), 38-43.

Tasnim, S., Hossain, M. M., \& Mazumder, H. (2020). Impact of rumors or misinformation on coronavirus disease (COVID-19) in social media. Journal of Preventive Medicine and Public Health.

Ufarte-Ruiz, M. J., Anzera, G. y Murcia-Verdú, F. J. (2020). Plataformas independientes de fact-checking en España e Italia. Características, organización y método. RevistaMediterránea de Comunicación, 11(2), 1-17. https://www.doi.org/10.14198/MEDCOM2020.11.2.3

Vizoso, Á., López-García, X., \& Pereira-Fariña, X. (2018). Habilidades tecnológicas como factor clave en el perfil del fact checker para la verificación de la información en la sociedad red. Estudos em Comunicação, 1(27), 105-126. https://doi.org/10.20287/ec.n27.v1.a07

Vizoso, Á., \& García, X. L. (2019). Newtral y Comprobado: experiencias de fact-checking durante la campaña electoral de las Elecciones Generales en España. In Puentes-Rivera, Fernández-Souto \& Vázquez-Gestal (Coords.), Debate sobre los debates electorales y nuevas formas de comunicación política (pp. 71-101). Vigo, España: Universidad de Vigo.

Zommer, L. (2014). El boom del fact checking en América Latina. Aprendizajes y desafíos del caso de Chequeado. Buenos Aires, Argentina: Chequeado. Recuperado de: https://n9.cl/a8q4u 